\title{
Hydroxymethylated resorcinol (HMR) priming agent for improved bondability of silicone modified wood glued with a polyvinyl acetate adhesive
}

\author{
R. Kurt • C. Mai · A. Krause • H. Militz
}

Published online: 21 February 2008

(C) The Author(s) 2008

Subject A hydroxymethylated resorcinol (HMR) was used as a coupling agent to improve glueability of silicone (aminofunctional polydimethylsiloxane) modified pine sapwood (Pinus sylvestris) with polyvinyl acetate (PVAc). Priming with HMR did not significantly increase tensile shear strength of unmodified and silicone treated wood under dry conditions. Under wet conditions, tensile shear strength of the control specimens was increased by $37 \%$ and of the silicone modified specimens by $13 \%$. Despite of higher shear strength under wet conditions, the primed silicone treated specimens displayed lower degree of wood failure than the unprimed treated specimens.

\section{Introduction}

Over the last years, a wide variety of silicon compounds have been applied to modify wood and to render the hydrophilic properties of wood more hydrophobic (Mai and Militz 2004, Donath et al. 2004, Donath et al. 2006, Weigenand et al. 2007). In practice, linear polydimethylsiloxanes (silicones) in particular are used as sealants on various surfaces. The presence of these compounds on the wood surface can delay or prevent the adhesive

R. Kurt

Faculty of Forestry, KSU,

46060 Kahramanmaras, Turkey

R. Kurt

e-mail: ramazankurt@yahoo.com

C. Mai $(\bowtie) \cdot$ A. Krause $\cdot$ H. Militz

Wood Biology and Wood Products, Burckhardt Institute,

Georg-August University Göttingen,

Büsgenweg 4,

37077 Göttingen, Germany

e-mail: cmai@gwdg.de wetting of the surface and proper curing. Thus, joints that are made of silicone modified lumber are considered to have poor bonding properties and reduced shear strength.

Coupling agents can be used to improve bonding properties of wood surfaces. They are molecules with dual functionality. In use, one part of the molecule promotes adhesion to one surface (e.g. a wood surface) while another part of the molecule adheres to the surface of another material (e.g. an adhesive polymer) (Vick et al. 1995, 1998). Hydroxymethylated resorcinol (HMR) consists of mono-, di- and trihydroxymethylated resorcinol (Vick et al. 1995). It has been used as an effective coupling agent for adhesive bonding of wood. Surface treatment with HMR was found to improve bondline resistance to moisture and enhance adhesion to wood for epoxy, phenol formaldehyde, phenol resorcinol formaldehyde, polymer/isocynate, melamine formaldehyde, urea formaldehyde, and melamine formaldehyde adhesive (Vick et al. 1998).

This study investigates the effect of HMR priming on the tensile shear strength of silicone modified wood joints that are glued with polyvinyl acetate (PVAc) adhesive.

\section{Experimental}

Assembly blocks were prepared from kiln dried Scots pine (Pinus sylvestris) sapwood that was free of defects. The average density of wood blocks was $515 \mathrm{~kg} \mathrm{~m}^{-3}$ at $12 \%$ moisture content. Pine sapwood blocks (600 (long) $\times 130 \times$ $6 \mathrm{~mm}^{3}$ ) were treated with HANSA ASE 8130 (CHT R. Beitlich $\mathrm{GmbH}$, Germany), a micro-emulsion with an ingredient content of $57 \%$ (40\% silicone). The emulsion contains an amino-polydimethylsiloxane (silicone) compound bearing primary amino-propyl groups and a nitrogen content 
of $0.25 \%$. The number of dimethylsiloxane subunits in the silicone molecules amounts to 300-400. The treatment was conducted as described previously (Weigenand et al. 2007) and resulted in a weight gain in the range of $25-32 \mathrm{~kg} \mathrm{~m}^{-3}$. The active ingredient concentration was $5 \%$. After the treatment, the specimens were conditioned in a climate chamber at $20{ }^{\circ} \mathrm{C}$ and $65 \%$ r.h.

Prior to the application of HMR or PVAc glue, the surface of the blocks was planed using a thicknesser. A 5\% aqueous HMR solution was prepared according to Vick et al. (1996) and applied on silicone-treated and untreated blocks; the application rate for HMR was $170 \mathrm{~g} \mathrm{~m}^{-2}$. Polyvinyl acetate (Jowacoll D4 with 5\% Hardener (195.35); Jowat AG, Germany) was spread on the wood blocks and the assemblies were placed in a hydraulic press to exert required pressure of $0.5 \mathrm{~N} \mathrm{~mm}^{-2}(120 \mathrm{~min})$ over the entire bonding area. The bond strength of the glued specimens was tested in longitudinal tensile shear according to the requirements of EN 302-1 (European Standard 1992). All specimens were tested under dry and wet conditions. Ten replicates were used for each treatment.

Analyses of variance (ANOVA) were conducted to determine sources of variation in tensile shear strength as affected by modifications, priming with HMR and testing conditions using the Statistical Analysis System (SAS) program (SAS Institute 2001). Specimens were grouped into two main groups which were dry and wet testing conditions. Comparisons of mean shear strengths were made by the Bonferroni (Dunn) t-test. When the differences exceeded the $\alpha=0.05$ level of probability, the differences between means were considered significant.

\section{Results and discussion}

Mean dry and wet shear strengths of specimens ranged between $7.7-8.3 \mathrm{~N} \mathrm{~mm}^{-2}$ and $4.4-6.0 \mathrm{~N} \mathrm{~mm}^{-2}$, respectively (Table 1). Silicone treatment did not affect the bonding strength of the specimens under dry and wet conditions, although the tested linear polydimethylsilicones are considered to impede gluing. It can, however, be assumed that planing specimens'surface using a thicknesser prior to gluing partly removed the silicone layer on the surface so that HMR or PVAc could directly get in contact with the wood substrate. Still, it was shown that the silicone microemulsion is able to penetrate deeply into the wood substrate and is deposited both in the lumens and in the cell wall (Weigenand et al. 2007). Under dry testing conditions, strength of the untreated controls and of the modified specimens was not significantly increased through priming with HMR within a confidence interval of $\alpha=0.05$.

In contrast, priming increased wet strength of the control specimens by $37 \%$ and of the modified specimens
Table 1 Mean values of tensile shear strength $\left(\mathrm{N} \mathrm{mm}^{-2}\right)$, their Bon groupings and average wood failure (\%)

Tabelle 1 Mittlere Zugscherfestigkeiten $\left(\mathrm{N} / \mathrm{mm}^{2}\right)$, statistischer Test auf signifikante Unterschiede sowie durchschnittlicher Holzbruchanteil $(\%)$

\begin{tabular}{|c|c|c|c|c|c|c|}
\hline \multirow[t]{2}{*}{ Sample ID } & \multicolumn{3}{|c|}{ Dry Condition } & \multicolumn{3}{|c|}{ Wet Condition } \\
\hline & Mean & B.G. ${ }^{\mathrm{a}}$ & W.F. & Mean & B.G. ${ }^{a}$ & W.F. \\
\hline Control-Unprimed & $7.73 \pm 0.40$ & A & 100 & $4.41 \pm 0.19$ & A & 30 \\
\hline Modified-Unprimed & $8.08 \pm 0.50$ & A & 95 & $4.87 \pm 0.20$ & B & 20 \\
\hline Control-Primed & $8.32 \pm 0.67$ & A & 80 & $6.03 \pm 0.32$ & $\mathrm{C}$ & 60 \\
\hline Modified-Primed & $8.19 \pm 0.52$ & A & 75 & $5.52 \pm 0.26$ & D & 10 \\
\hline
\end{tabular}

B.G.: Bon grouping ( ${ }^{\mathrm{a}}$ Means with same letters are not statistically different), WF: Wood failure

by $13 \%$, respectively (Table 1 ). Bonferroni t-test results revealed that these increases in wet strength were significant $(\alpha=0.05)$. The proportion of wood failure was low under wet conditions, except for primed untreated wood $(60 \%$, Table 1). Under wet conditions, the unprimed treated and untreated specimens displayed a higher proportion of wood failure than primed, silicone-treated wood, although the shear strength of the latter was significantly higher. Higher shear strength can be explained with reduction in water uptake due to silicon treatment. Hydrophobic silicone might have prevented the penetration of water molecules into the interface between PVAc and the wood surface.

\section{Conclusion}

The introduction of HMR priming on silicone modified wood surfaces did not increase the dry strength, but HMR priming was effective in improving the wet strength. From these results it can be concluded that the PVAc adhesive can be used to bond silicone modified wood only for interior uses. Overall, the results suggest that the use of the HMR priming agent for improving bonding properties of silicone modified wood needs further research. The bonding properties of other types of silicon compounds, e.g. amino silicone (macro emulsions), quaternary ammonium silicones, silane/siloxane, silicone-wax and silicate should be tested with different thermoplastic and thermosetting adhesives using not only HMR but also other surface agents.

Acknowledgement R. Kurt extends special thanks to Deutsche Forschungsgemeinschaft and The Scientific and Technical Research Council of Turkey (TUBITAK) for their scholarships during this study.

Open Access This article is distributed under the terms of the Creative Commons Attribution Noncommercial License which permits any noncommercial use, distribution, and reproduction in any medium, provided the original author(s) and source are credited. 


\section{References}

Donath S, Militz H, Mai C (2004) Wood modification with alkoxysilanes. Wood Sci Technol 38:555-566

Donath S, Militz H, Mai C (2006) Creating water-repellent effects on wood by treatment with silanes. Holzforschung 60:40-46

European Standard (1992) EN 302-1: Adhesives for load bearing timber structures - test methods - Part 1: Determination of bond strength in longitudinal tensile shear

Mai C, Militz H (2004) Modification of wood with silicon compounds. Inorganic silicon compounds and sol-gel systems; a review. Wood Sci Technol 37:339-348

SAS Institute (2001) SAS/STAT release 8.2. SAS Institute, Cary
Vick CB, Christiansen AW, Okkonen EA (1998) Reactivity of hydroxymethylated resorcinol coupling agent as it affects durability of epoxy bonds to Douglas fir. Wood Fiber Sci 30(3):312-322

Vick CB, Richter K, River BH, Fried Jr AR (1995) Hydroxymethylated resorcinol coupling agent for enhanced durability of bisphenol-a epoxy bonds to Sitka spruce. Wood Fiber Sci 27(1):2-12

Vick CB, Richter KH, River BH (1996) Hydroxymethylated resorcinol coupling agent and method for bonding wood. U.S. patent 5543487

Weigenand O, Militz H, Tingaut P, Sèbe G, de Jeso B, Mai C (2007) Penetration of amino-silicone micro- and macro-emulsions into Scots pine sapwood and the effect on water related properties. Holzforschung 61:51-59 